\title{
SEGREGATION OF NORMAL AND CANCER CELLS BASED ON IMPEDANCE CHARACTERISTICS OF SINGLE CELL
}

\author{
Shobha Gupta \\ Electrical Engineering Department, College of Engineering and Management, \\ Kolaghat, W.B, India \\ Vivekkant Jogi \\ School of Engineering and Information Technology, MATS University, \\ Raipur, C.G, India
}

\begin{abstract}
Study of single cell with respect to its electrical characteristics is a promising noninvasive tool for modelling bio device for early diagnosis of cancer. In this paper, a relative study of cell impedance based on electrical model of a single cell is presented for fabrication of biodevice which will be helpful in distinguishing normal cells from malignant or differentiating cells of same phenotype. The bioimpedance of a cell per unit surface length has been studied and simulated for a range of frequency inputs. The simulation is done in MATLAB environment which shows that the capacitance of the cellular membrane is effective till a particular range of input frequency, after which, the conductivity of cell plays a significant role in governing the permeability of cells.
\end{abstract}

Key words: bioimpedance, MATLAB, electrical model, normal and cancer cells.

Cite this Article: Shobha Gupta, Vivekkant Jogi, Segregation of Normal and Cancer Cells Based on Impedance Characteristics of Single Cell, International Journal of Advanced Research in Engineering and Technology, 10 (3), 2019, pp 148-155. http://iaeme.com/Home/issue/IJARET?Volume=10\&Issue $=3$

\section{INTRODUCTION}

Cancer is a major disease affecting a large number of people and has defied the development of an effective methodology of treatment so far. If the cancer is detected at an early stage, there are chances of survival of the individual [1]. Metastasis that results in the spread of cancer to various parts of the body introduces a new dimension of different types of cancer (lung cancer, breast cancer, ovarian cancer, prostate cancer, melanoma etc) needing different treatments. Regulatory function homeostasis is an important regulatory function of the human body. The human body is some sort of a social order of about 100 trillion cells organized into different functional structures, some of which are called organs. Each functional structure contributes its share to the maintenance of homeostatic conditions (a pseudo-static equilibrium) in the extracellular fluid (fluid surrounding cells) which is called the internal environment of the human body. As long as normal conditions are maintained in this internal environment, the cells 
continue to live and function while contributing their share to the maintenance of homeostasis [1]. When the controlling signals are disabled, diverted or distorted, the homeostasis is disturbed and may result in uncontrolled proliferation and cancer. If cancer is detected at an early stage, then the chances of survival increases [2]. Hence, efforts are made in early diagnosis of cancer.

The approach for designing new methods and technologies for early diagnosis of cancer has been always a matter of concern. This is because the membrane voltage is highly dependent on the heterogeneity of the tissues. This complexity could be addressed either by considering the voltage status of a single cell or by taking into consideration the heterogeneous nature of the tissue membrane. While considering the heterogeneous nature of tissues, the type of tissue has also to be considered because each tissue may have different characteristics. So, the present paper takes into consideration a single cell model to understand electrical behaviour of cells within given frequency range. Bioimpedance technique is a non-invasive, label free and quantitative method to analyze the cell status $[1,3]$. This method is easy to use and cost effective. With the development of MEMS and Nano technology, the equipment have the advantage of being compatible and economical.

\section{ELECTRICAL MODEL OF A SINGLE CELL}

Bioimpedance measurement is a promising tool to distinguish between the normal and abnormal cells since it can monitor the physiological variation in terms of electrical parameters for the same type of cell line at different stages of malignancy $[3,4]$.

Depending on the characteristics of the cell, it can be modelled in form of electrical parameters. It has been shown that the current flowing through a cell experiences opposition to its flow, both through extracellular and intracellular medium [5,6,7]. This opposition is termed as bioimpedance of a cell. Each cell consists of a membrane submerged in an extracellular medium. In fact, all the cell organelles are surrounded by their respective membrane. The cell membranes are composed of a bilayer of highly mobile lipid molecules that electrically behaves as an insulator (dielectric). The insulating properties of the cell membrane also restrict the movement of charged ions and electrons across the membrane except through specialized membrane spanning protein ion channels [5-9] and membrane spanning protein semiconductors [10] respectively. Thus the lipid structure of a cell membrane makes it relatively semiconductors [9] respectively. So, the lipid structure of a cell membrane makes it relatively impermeable to the passage of charged molecules. By considering all these electrical characteristics of a cell, it can be modelled to its electrical equivalent circuit. $[11,12,13]$.

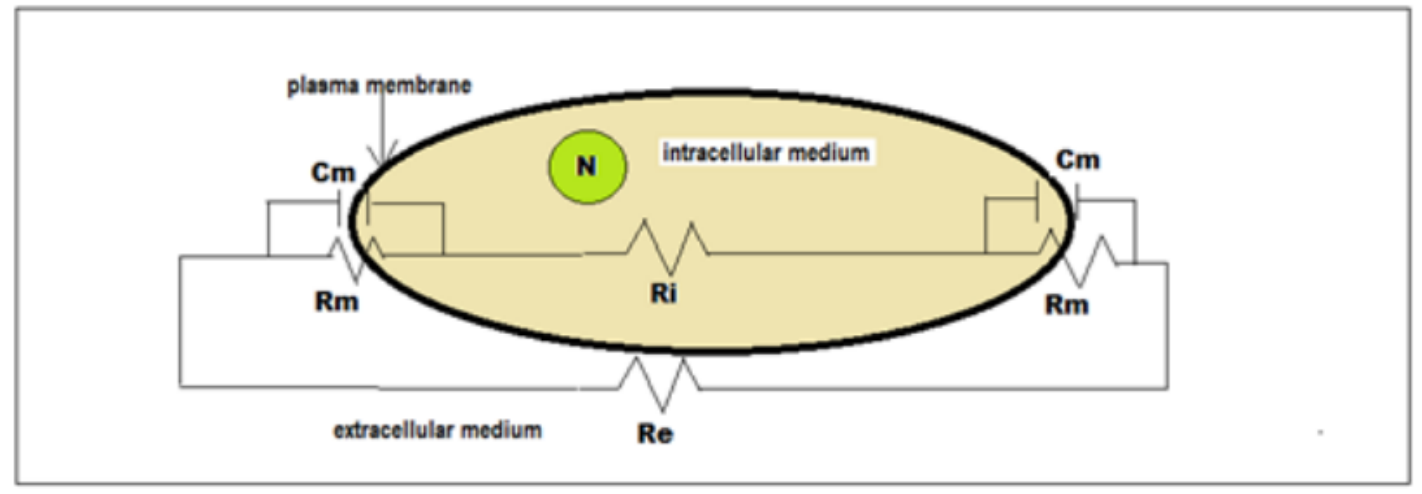

Figure 1 Equivalent Electrical model of a single cell

When an electric potential is applied across a cell, its membrane acts as a parallel combination of membrane resistance $\mathrm{R}_{\mathrm{m}}$ and capacitance $\mathrm{C}_{\mathrm{m}}$ in series with the intracellular 
medium resistance $\mathrm{R}_{\mathrm{i}}$. The extracellular medium acts as resistance $\mathrm{R}_{\mathrm{e}}$ in parallel to the above combination. The equivalent electrical model of a single cell is as shown in Fig. 1:

The parallel impedance of $\mathrm{R}_{\mathrm{m}}$ with $\mathrm{C}_{\mathrm{m}}$ could be given by:

$$
\begin{aligned}
& \left(R_{m}|| 1 / j \omega C_{m}\right) \\
= & \left(\mathrm{R}_{\mathrm{m}} / \mathrm{j} \omega \mathrm{C}_{\mathrm{m}}\right) / \mathrm{R}_{\mathrm{m}}+\left(1 / \mathrm{j} \omega \mathrm{C}_{\mathrm{m}}\right) \\
= & \mathrm{R}_{\mathrm{m}} /\left(1+\mathrm{j} \omega \mathrm{C}_{\mathrm{m}} \mathrm{R}_{\mathrm{m}}\right)
\end{aligned}
$$

Hence the impedance of both the ends of cellular membrane becomes:

$$
\begin{aligned}
& R_{m} /\left(1+j \omega C_{m} R_{m}\right)+R_{m} /\left(1+j \omega C_{m} R_{m}\right) \\
& =2 R_{m} /\left(1+j \omega C_{m} R_{m}\right) \\
& =\left[2 R_{m} /\left(j \omega C_{m} / 2\right)\right] /\left[2 R_{m}+\left\{1 / j \omega\left(C_{m} / 2\right)\right\}\right]
\end{aligned}
$$

Hence, the equivalent circuit could be deduced as in Fig. 1(a):

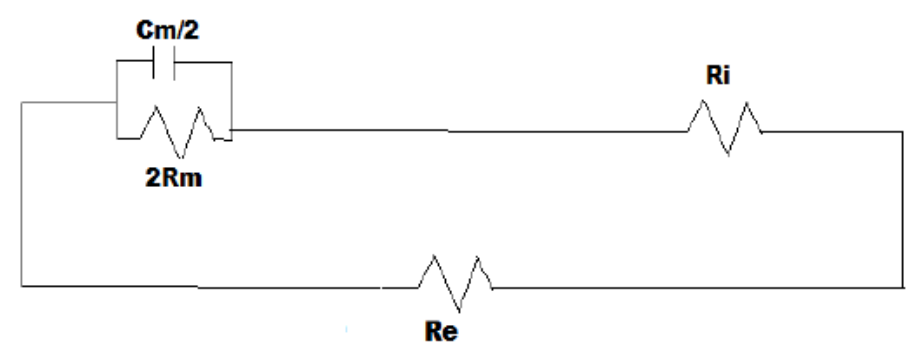

Figure 1(a) Simplified Electrical model of a single cell

The equivalent intracellular impedance is given by

$\left[2 \mathrm{R}_{\mathrm{m}} /\left(1+\mathrm{j} \omega \mathrm{C}_{\mathrm{m}} \mathrm{R}_{\mathrm{m}}\right)\right]+\mathrm{Ri}$

And overall cellular impedance offered to the electrode is

$$
\left[\left\{2 \mathrm{R}_{\mathrm{m}} /\left(1+\mathrm{j} \omega \mathrm{C}_{\mathrm{m}} \mathrm{R}_{\mathrm{m}}\right)\right\}+\mathrm{Ri}\right] \| \mathrm{R}_{\mathrm{e}}
$$

When current is injected through the extracellular medium, several situations may occur:

1. The current flows via the extracellular medium, bypassing the cell membrane. This occurs when cellular membrane capacitance does not allow any path for the current flow. Since, the capacitive reactance is given by $1 / \mathrm{j} \omega \mathrm{C}$, a capacitor offers high reactance to low frequency input. Thus the membrane acts as insulator and does not allow current to pass through.

2. The current pass through the cell membrane $C_{m} \| R_{m}$ and consequently through the intracellular medium $\mathrm{R}_{\mathrm{i}}$. As the capacitive reactance is inversely proportional to the input frequency, it offers low reactance for high frequency input. If the frequency is high, the capacitive reactance is negligible with respect to the membrane resistance. Hence, $R_{m}>>X_{c}$. Also, the conductivity of the cellular membrane is very low.

So, the equivalent model for the given frequency could be simplified as in Fig. 1(b): 


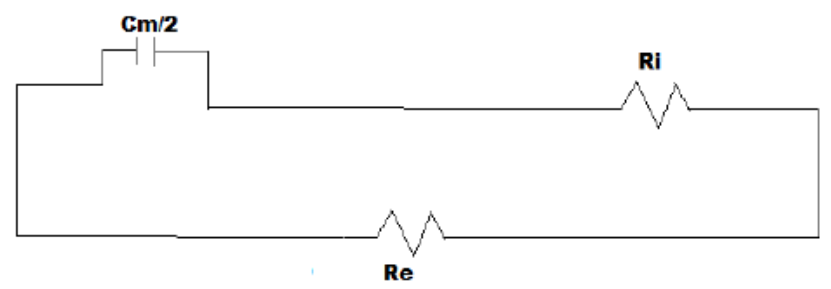

Figure 1 (b) Simplified Electrical model of a single cell at high Frequency

The cellular impedance could be expressed as:

$$
\left\{\mathrm{R}_{\mathrm{i}}+\left(2 / \mathrm{j} \omega \mathrm{C}_{\mathrm{m}}\right)\right\} \| \mathrm{R}_{\mathrm{e}}
$$

This shows that the same cell could be represented by different equivalent circuit for different input frequency and/or different status of the cellular membrane. This model is used to find out the cutoff frequency of the given breast and white blood cells sample. The simulation is done in MATLAB environment for finding the frequency response of the given cell lines.

\section{IMPEDANCE CHARACTERISTICS BASED ON THE GIVEN MODEL}

Impedance is a complex parameter in electrical terms, which has real and imaginary components. The impedance (per unit area) of a single cell, for normal and malignant human breast cells [14] and white blood cells [15], is considered for realizing the impedance characteristics. The breast cells considered are MCF-10A, MCF-7, MDA-MB-231 and MDAMB-435S, which are normal cell, early stage, invasive, and late stage cancer cells respectively. The $\mathrm{x}$-axis is frequency in hertz and $\mathrm{y}$-axis is Impedance in ohms per unit length. The Impedance is taken in per unit length as the cell size changes with the status.

The white blood cells considered [15] are normal tonsillar B cells, Magala cell line(transformed by EBV: dividing but non-cancerous) and cancer cells: Farage (NonHodgkin's lymphoma), Raji, Bjab and Daudi(Burkitt's lymphoma).

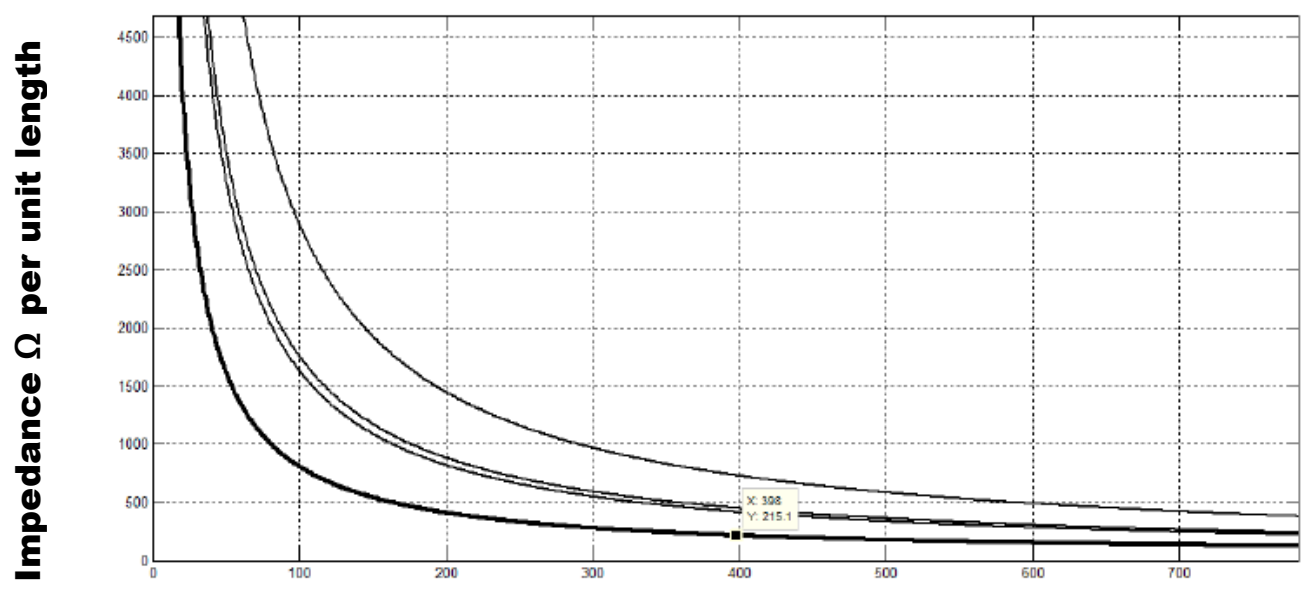

Frequency in Hz---------- $\rightarrow$ 


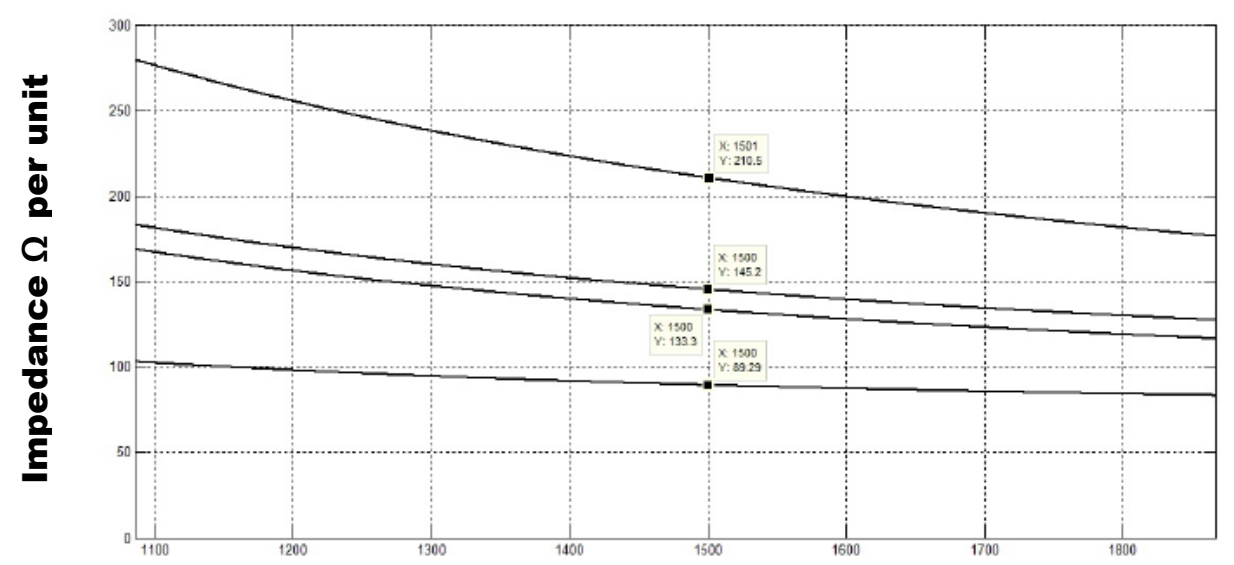

Figure 2 (a)

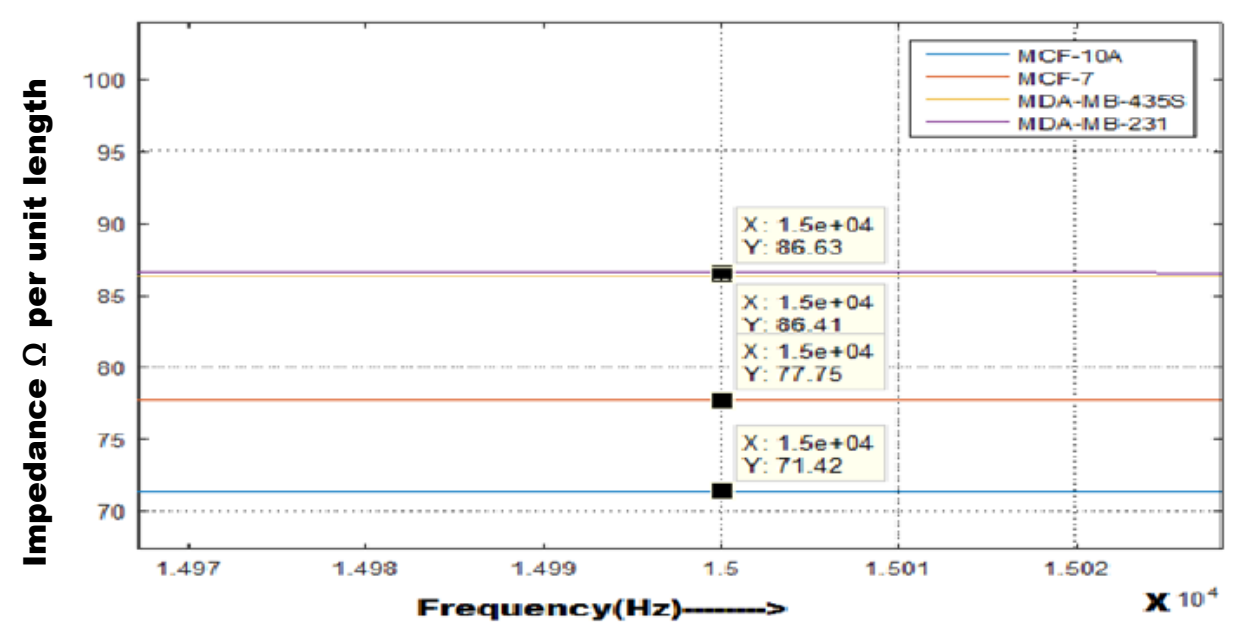

Figure 2 (c)

Figure 2 (a), (b), (c) representing Impedance per unit length for considered breast cells

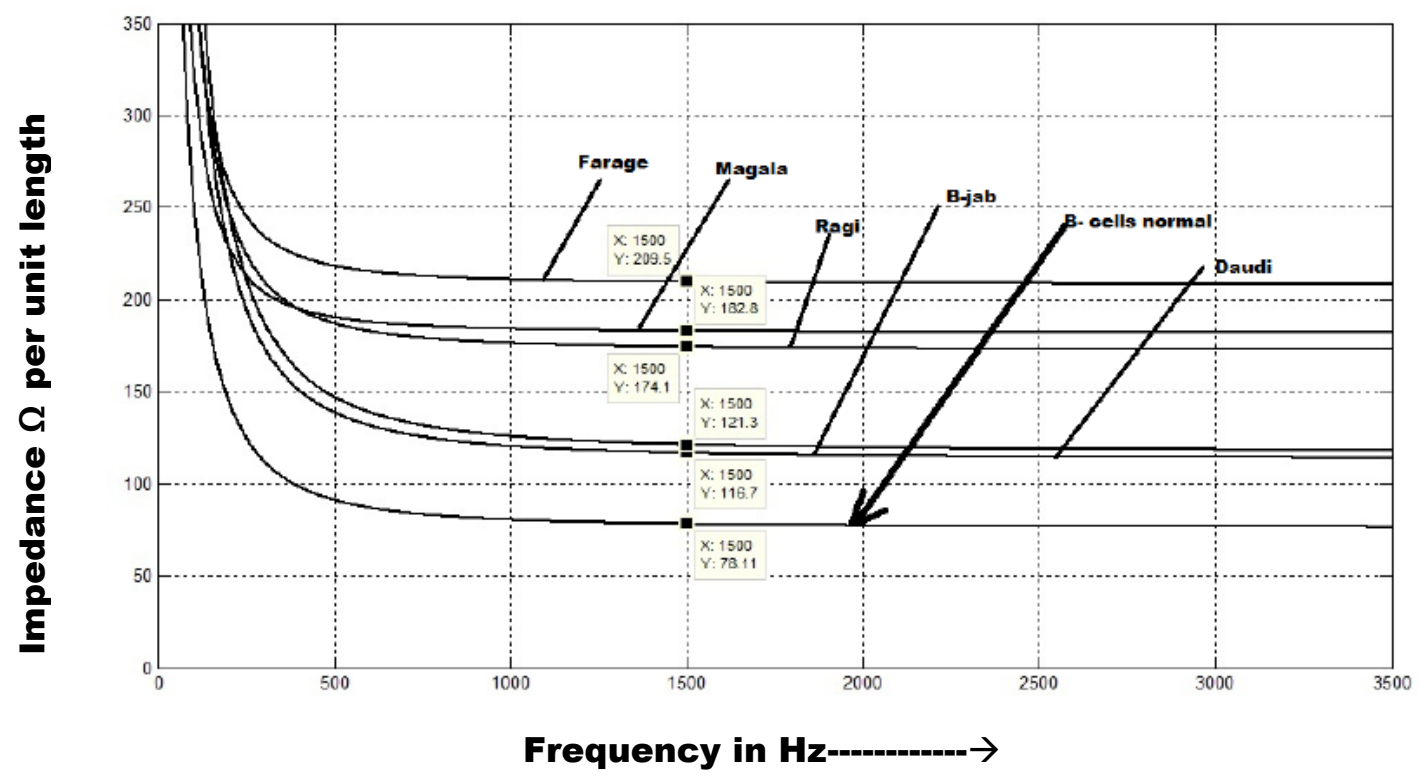

Figure 3 Frequency response of considered human white blood cells for different frequency 


\section{RESULTS, DISCUSSION AND CONCLUSION}

The frequency based biological impedance spectrum is a representation of its biological behaviour and subsequently cell status. This could be used as a basis to segregate the normal cells and the malignant cells. It is also noteworthy that the decreased cell membrane capacitance is indication of poor prognosis [14-18]. This is because the differentiating cells or cancerous cells are more permeable and have decreased cellular capacitance.

But the frequency range for cell characteristics evaluation has to be wisely chosen. For skin cancer detection by EIS (Electrical Impedance Spectroscopy), the frequency range between $10 \mathrm{~Hz}$ to $100 \mathrm{KHz}$ gives the appropriate results [16]. This is because for the given arrangement, frequencies less than $10 \mathrm{~Hz}$ has the electrolyte/electrode capacitance dominating the system impedance and at frequencies greater than $100 \mathrm{KHz}$, the system impedance only includes the resistance of the culture medium, electrodes and wiring. It was shown that the frequency of $1.455 \mathrm{KHz}$ was found to be the optimum frequency for discrimination of normal and cancer skin cells [16]. This EIS measurement included the parameters of the measuring equipment and concluded for the given frequency. The detection of human colon cells HT29 (grade1) and SW48 (grade 4) was done within the frequency range of 1 to $20 \mathrm{KHz}$ and stages of the cancer cell could be detected [17].

For finding out the electrical characteristic of normal and cancer cells of lung, liver and breast tissues, a frequency range of 0 to $10000 \mathrm{~Hz}$ was appropriate [18].This is because the cells from different tissue origins possess different electrical characteristics and the cellular impedance varies for different tissue type.

The present model gives a simple approach for frequency based segregation of the normal human breast and white blood (B tonsillar) cells from their counterpart cancer cells. A frequency range of 0 to $500 \mathrm{KHz}$ is used to analyse the impedance response of the breast cells and white blood cells. The outcome is as follows:

A. The impedance response of cells shows that the slopes for normal cells and their cancer counter parts are different at a particular frequency. This implies that these cells have different relaxation frequencies. The output curve shows decreased value of relaxation frequency for normal cells as compared to their cancer counterparts. This response corresponds to the previous research results [17].

B. Impedance response of white blood (B cells) has faster exponential decay than breast cells: The frequency response for white blood cells (B-cells) shows faster exponential decay than breast cells. This indicates that the change in permeability of white blood cells is faster as compared to breast cells under same environment.

C. Minimum Frequency after which conductivity of cytoplasm becomes predominant and the impedance is distinctly observable is different for breast cells and white blood cells. From the figure 2 , it is evident that the frequency above which the conductivity of the cytoplasm is predominant in breast cells is $15 \mathrm{KHz}$. From previous studies, the most sensitive frequency to distinguish normalized impedance of skin cells (A431 and HaCaT cell lines) was $1.465 \mathrm{KHz}$. The impedance curves for both breast and white blood cells have been shown at $1.5 \mathrm{KHz}$. The breast cells show the influence of membrane capacitance still affecting the overall cell behaviour but the white blood cells show relatively constant impedance response at $1.5 \mathrm{KHz}$. The breast cells exhibit relatively constant impedance characteristics after $15 \mathrm{KHz}$. This indicates that the membrane capacitance of the breast cells decreases after more frequency as compared to the white blood (B tonsillar) cells.

The cellular relative impedance measurement could be employed as an important tool for measuring the status of the cell. The cells of different origins exhibit different electrical characteristics and have different cutoff frequencies at which the membrane capacitance 
minimizes. This implies that different cells of different tissues have different capabilities of withstanding external field. This may be useful in diagnosis of the cell status and also in drug delivery.

On contrary, the same type of cell shall exhibit distinct bioimpedance values for the same input with same frequency because the heterogeneity of tissues plays an important role for normalizing the data. The tissue type, structure and geometry play a vital role in designing the instrument for cell status analysis. Other parameters like cell permittivity, conductivity and polarization with the applied field, may be considered for results that are more accurate. The present work assumes that the cell culture is homogeneous in nature. Moreover, the varying values of electrical parameters of the cells, device probe and the medium have to be considered for increasing the accuracy of the results.

Besides the simplified assumptions, relative cellular impedance measurement could be employed as an effective tool for diagnosis of cancer concomitant with its stage.

\section{REFERENCES}

[1] A.C. Guyton and J. E. Hall, Textbook of Medical Physiology, $13^{\text {th }}$ Edition, 2016.

[2] Shobha Gupta, T.K.Basak and S. Chaudhuri; Retinoid dependent growth arrest and differentiation in melanoma, International Journal of Medical Engineering and Informatics, 2012, Vol.4, No.3, 231-243.

[3] Sami F. Khalil, Mas S. Mohktar and Fatimah Ibrahim; The Theory and Fundamentals of Bioimpedance Analysis in Clinical status Monitoring and Diagnosis of Diseases; Sensors(Basel), June 2014, V.14(6), 10895-10928

[4] Alireza Salmanzadeh, Michael B. Sano, Roberto C. Gallo-Villanueva, Paul C. Roberts, Eva M. Schmelz and Rafael V. Davalos; Investigating dielectric properties of different stages of syngeneic murine ovarian cancer cells; Biomicrofluidics; January 2013; 7(1); 011809-1 to 17

[5] Schwan H. P., Electrical properties of tissues and cell suspensions, in Advances in Biological and Medical Physics, Academic Press, New York, 1957, pp. 147-209

[6] Blad B., Baldetorp B., Impedance spectra of tumour tissue in comparison with normal tissue: A possible clinical application for electrical impedance tomography, Physiological Measurement, 17, Suppl 4A, 1996, pp. A105-115

[7] Charman R. A., Electrical Properties of Cells and Tissues, In Clayton's Electrotherapy 10th edition (eds. S.Kitchen and S. Bazin), London, UK, WB Saunders Company Ltd., 1996.

[8] Cone C. D., Variation of the transmembrane potential level as a basic mechanism of mitosis control. Oncology, 1970, 24, pp. 438-470.

[9] Cone C. D., The role of surface electrical transmembrane potential in normal and malignant mitogenesis, Ann. NY Acad Sci., 1975, 238, pp. 420-435

[10] Oschman J. L., Energy Medicine: The Scientific Basis, Edinburgh, England, Churchill Livingstone, 2000.

[11] Gupta Shobha and Jogi Vivekkant, Diagnosis of cancer based on Electrical Model of a single cell, Journal of Engineering and Applied Sciences, Vol.3, Issue 1, 2018, pp 129-133

[12] Hakan Solmaz, Yekta Ülgen and Murat Tümer, Design of a microcontroller Based ColeCole Impedance meter for testing Biological Tissues, IFMBE proceedings, September 2009, Vol 25/7

[13] Louis J. DeFelice, Electrical Properties of cell, Patch Clamp for Biologists, Plenum Press, Newyork, 1997 
[14] G Qiao, W Duan, C Chatwin, A Sinclair and W Wang, Electrical Properties of Breast cancer cells from impedance measurement of cell suspensions, Journal of Physics, 2010, Vol 224(1)

[15] Yulia Polevaya, Irina Ermolina, Michael Schlesinger, Ben-Zion Ginzburg and Yuri Feldman, Time domain dielectric spectroscopy study of Human cells: Normal and malignant white blood cells, Biochimica et Biophysica Acta (BBA)- Biomembranes, Elsevier, Vol. 1419, Issue 2, July 1999, pg. 257-271

[16] Fan Zhang, Tongyu Jin, Qingquing Hu, and Pingang He, Distinguishing skin cancer cells and normal cells using electrical impedance spectroscopy, Journal of Electroanalytical Chemistry, August 2018, Vol. 823, pp. 531-536

[17] S Abbasi, M. Janmaleki, M. Kazemi Moghadam, M. Abdolahad, S. Mohajerzadeh and H. Peirovi, Detection of different grade of cancerous cell regarding their impedance, World Congress on Medical Physics and Biomedical engineering, IFMBE Proceedings 39, 2013, pg 1416-1419.

[18] Mahmoud Al Ahmad, Zeina Al Natour, Farah Mustafa and Tahir A. Rizvi, Electrical Characterization of normal and cancer cells, IEEE Access Multidisciplinary, , Vol 6, 2018 pp. 25979-25989.

[19] Mahendra Pratap Singh and Dr. Anil Kumar Sharma, Eyes Detection Using Morphological Image Processing Through Matlab, International Journal of Advanced Research in Engineering and Technology (IJARET), Volume 4, Issue 7, November - December 2013, pp. $139-146$

[20] P Sridhar and K Bhanu Prasad, Fault Analysis in Hydro Power Plants Using Matlab/Simulink, International Journal of Electrical Engineering and Technology (IJEET), Volume 5, Issue 5, May (2014), pp. 89-99

[21] R R Mandal and U K Dewangan Finite Element Modeling of Beam with Eight Noded Brick Element Using Matlab, International Journal of Civil Engineering and Technology, 8(5), 2017, pp. 646-656

[22] Mr. Shrikant J. Honade, Height, Weight and Body Mass Index Measurement Using Matlab, International Journal of Advanced Research in Engineering and Technology (IJARET), Volume 4, Issue 5, July - August 2013, pp. 35-45

[23] Ravina K. Panchal, P. S. Swami and Dr. A. G. Thosar, Improving the Accuracy of Dga Interpretation for Detection of Incipient Faults Using Matlab Gui: International Journal of Electrical Engineering \& Technology, 9(4), 2018, pp. 124-133.

[24] M. Munadi, Mochammad Ariyanto, Joga D. Setiawan, M. Amir Abdullah, Ahmad Hasan Fauzi and Muhammad Nanda Setiawan, L1 Adaptive Control for Missile Longitudinal Dynamic Using Matlab/Simulink, International Journal of Mechanical Engineering and Technology, 9(10), 2018, pp. (1346) - (1355). 